\title{
ECOLOGICAL IMPLICATIONS OF THE UNDERSTANDING OF HUMAN BEING IN THE CLASSICAL CHINESE THOUGHT
}

\author{
Antoaneta NIKOLOVA \\ Leipzig University, Germany, South-West University "Neofit Rilski”, Bulgaria \\ E-mail: tonishan1@yahoo.com
}

\begin{abstract}
The paper aims at discussing the ecological implications of the understanding of the human being in the Classical Chinese thought. The study consists of three main parts.

In the first one, the peculiarities of the Chinese thought as a philosophy of dynamism are discussed. I argue that in contrast to the Western thought, where the main ontological question is connected with the issue of essence and the epistemological approach is based on the opposition of subject and object, the Chinese thought reveals reality in terms of dynamism, where the most important concepts are these of processes, relations and transformations.

In the second part, I analyse the place of human beings in this dynamic universe in terms of three different perspectives: (i) their relations; (ii) their actions/interactions; and (iii) their value. I point out that it is the harmony that could be defined as the most privileged position in the Chinese universe.

In the third part, I discuss two main kinds of ecologically wise behaviour of human beings that are in accordance with the dynamic nature of the universe: (i) the Confucian idea of the outer harmonisation of the human society with the patterns of transformation in the Universe and (ii) the Daoist idea of the inner achievement of the pivot of transformation within oneself.

In the conclusion, I outline the idea that the combination of inner and outer activity of harmonisation with reality could be used as an example of wise ecological behaviour and attitude to nature.

The work on the paper is part of an individual project "Perception of Eastern Teachings in Europe" funded by the European Union through the Marie Sklodowska-Curie Action, Horizon 2020, grant No. 753561.
\end{abstract}

KEYWORDS: Confucianism, Daoism, Yijing, Daodejing, processual ontology, harmony, balance, ecological consciousness

\section{Introduction}

One of the main problems of our time is the ecological crisis. It is regarded not only as a result of "certain economic, political and social factors", but also as "a moral and spiritual crisis whose resolution requires a wider philosophical and religious understanding of ourselves as natural beings embedded in cycles of life and dependent on ecosystems" (Girardot, 2001, p. XIV). This understanding means to reconsider our views of the world, to explore the basis of our thinking, to try to see without prejudice the ecological potential of our spiritual heritage as well as that of cultures other than ours. In this regard, the ecological implications of Asian cultures are of great interest for many scholars.

In this paper I aim to present one of the aspects of the ecological potential of Chinese traditions, namely the ecological implications of the understanding of the human being.

The paper consists of three parts. In the first one, I analyse the main principles of the Chinese thought. In the second part, I outline the understanding of the human being in accordance with these principles. In the third part, I make conclusions about the ecological meaning of this understanding.

\section{Peculiarities of the Chinese thought}

The main and most important specificity of the Chinese thought is that it regards reality in terms of dynamics. This approach is very different from the European perception of reality that is understood - as Heidegger explains - through the Parmenidean wonder that "there is being". Parmenides described being as single, homogenous, boundless, eternal, unchangeable and immovable:

... what is, is uncreated and indestructible, alone, complete,

immovable and without end. Nor was it ever, nor will it be; for

now it is, all at once, a continuous one

(Parmenides, On Nature, VIII, English translation: John Burnet, 1892, p. 175)

This being is a mental construct that is achieved through reasoning. As Vladimir Malyavin (2016) points out, for some reason the Greek thought decided that words (especially nouns) designate some reality behind them. They regarded this as the true reality, reality of ideas, whose perishable shadows the real things are. In such a way, reality was split in two: the true reality as it is achieved by 
reasoning and the visible reality, as it is perceived by the senses. In that, the two realities have no equal value. The splitting of reality leads to a "hierarchical view that one side of the distinction was worthy, good and true, while the other was at best a hindrance with which one had to live, or at worst something evil that was to be eradicated if we were ever to find the Truth" (Burik, 2009, p. 11).

In Ancient Greek philosophy, the concept of being has two counterparts. One of them is "nonbeing". It is unthinkable and impossible. It is revealed as its negative opposite that has no ontological validity and meaning in itself and functions only in order to outline the characteristics of being.

The other counterpart is the concept of "becoming". According to Parmenides, change is a mere appearance, an illusion. Although Heraclitus presented the opposite view describing reality as an allembracing permanent transformation, the ideas of Parmenides form the major trend in Western philosophy. Therefore, the main ontological question of this philosophy is connected with the issue of essence and its epistemological approach is based on the opposition of subject and object regarded as more or less stable entities.

The Chinese view of reality in terms of dynamism is different and leads to other conclusions.

In this philosophy, there is no idea of Being as some intelligible reality. Therefore, there is no splitting of reality and opposition of transcendent and immanent, spiritual and material.

Chinese philosophy is all about the living life as it is, here and now, life per se, without a question who bears it because there is nothing outside it. Real life is not fixed and still. The entire world is a flow of living energy. In this flow, there are no things as separated and isolated entities but vortexes of energy and energy processes. On the one hand, these processes are in constant transformations, they unceasingly change. On the other hand, they are in multiple relations and communications with other processes.

Therefore, the most important notions of these thought are: 1) transformations and 2) relations.

For the Chinese thought, "the real reality... is the very transformation" (Malyavin \& Vinogrodskii, 1994, p. 2). The Chinese idea of change is presented in "Yijing", "The Book of Changes", an important treasure of Chinese culture and philosophy, one of the Five Confucian Classics. According to “Yijing”, the main characteristic of the world is change, “易”. Change might be a slight modification, 變, bian, or an entire transformation, 化, hua. Daoism also views the world as a huge transformation and everything in it as a process of transformation and change. As Ames and Hall correctly note: "As a parody to Parmenides, who claimed that "only Being is", we might say that for the Daoist, "only beings are", or taking one step further in underscoring the reality of the process of change itself, "only becomings are" (Ames \& Hall, 2003, pp. 13 -14).

In fact, if reality is a huge flow of living energy, it is hard to distinguish different "becomings" among the wholeness of transformation. The processes in it are not isolated per se, but are in mutual connections, simultaneously transforming and changing each other: "Daoists do not think in terms of essences, entities or ideas, but in terms of relations, functions, and influences" (Malyavin \& Vinogrodskii, 1994, p. 2). Everything is regarded in its connection, communication and openness to everything else. Therefore, there are no isolated entities but "processual events" that are open, flexible and dynamic. It is possible to distinguish only "some unique current or impulses within a temporal flow" and all of them "are porous, flowing into each other in the ongoing transformation" (Ames \& Hall, 2003, p. 15).

Relations in this fluid universe are always mutual, not one-sided. Mutuality is one of the most important secrets when perceiving the world according to Daoism and Chinese philosophy as a whole:

此兩者，同出而異名，同謂之玄。玄之又玄，衆妙之門1。(Daodejing, 1) ${ }^{2}$

In the Chinese thought, this "togetherness" encompasses two basic categories: absence and presence, wu, 無, and you, 有. They are often incorrectly translated in terms of the important pairs of the Western thought "being" and "non-being".

\footnotetext{
${ }^{1} 29.09 .2019<$ https://ctext.org/dao-de-jing $>$

2 "These two together arise, but are differently called. Togetherness is a secret inherent" (my translation - A. N.)

29.09.2019.<https://ctext.org/dao-de-jing >.
} 
The two concepts, however, have different prerequisites and grounds. While the concepts of being and non-being in Indo-European languages are derived from the verb "to be" and are therefore connected with the issue of existence, the Chinese terms wu, 無, and you, 有, mean "to have not" and "to have" referring therefore "to the area of possessing not to the area of being" (Kobzev, 1994, p. 516). This is a very important difference that represents two different viewpoints, two different approaches to reality - a subjective one, i.e. an approach from the position of something separated (in the case of being and non-being) and an objective one - from the position of the whole which contains something (in the case of wu, 無, and you, 有). As Graham points out "in Chinese, one approaches existence from something outside... which has, in which there is, the thing in question" (Graham, 1959, p. 81). The Western thought, however, is "grounded in Greek and Latin" and "has generally approached the question from the opposite direction, from the thing which "is" or "exists" (ibid.). So, the difference between the two pairs - "being" and "non-being" and wu, 無, and you, 有 is a difference between the vision of reality in terms of essence and the vision of reality in terms of relations.

The Classical Chinese language corresponds to the latter one. It is "in harmony with the processual thinking, not with substantive ontology" (Burik, 2009, p. 104). Here "words do not name essences. Rather, they indicate always-transitory processes and events" (ibid.). Therefore, as Marcel Granet points out, most Chinese words keep some kind of living meaning and predominantly remain verbs (Granet, 2008, p. 28). In their rather free but nevertheless adequate interpretation of the Chinese character, Ernest Fenollosa and Ezra Pound explain that in reality things and action are not separated: "a true noun, an isolated thing, does not exist in nature. Things are only the terminal points, or rather the meeting points of actions, cross-sections cut through actions, snapshots. Neither can a pure verb, an abstract motion, be possible in nature. The eye sees noun and verb as one: things in motion, motion in things, and so the Chinese conception tends to represent them" (Fenollosa, Pound, 1936, p. 10).

We could check this assertion regarding the pictogram for the very concept of "thing" in the Chinese language. In one of the words for "thing", the connection between "thing" and "motion" seems obvious. This is the word shi, 事, that means ,thing“" in terms of "occupation”, "affair", "work". It is composed by a hand holding something to perform some action. In one of the interpretations it holds a "flag or hunting weapon" "to perform one's job"3. In another interpretation, this is a "hand holding a brush which writes words" motion.

The word that is used in ancient texts is 物. It is composed of the radical for cow or ox, 牛牛, niú, and phonetic bloody-knife, 勿, wù" (ibid.). The meaning derives from the fact that "a cow was property that you could kill and eat, thus a thing" (ibid.). So, on the one hand this character is connected with the idea for action pointing what we could do with something. On the other hand, however, it seems to be against the idea of mutuality presenting a subject operating one-sidedly on an object. Is this a simple cutting of reality into separated pieces?

Yes, this meaning exists here. It is in accordance with the idea of Daoism that "since the invention of words and language, human beings have come to use language to say things about the world, and this has had the effect of cutting up the world in our eyes. When humans invent a name, suddenly the thing named appears to stand apart from the rest of the world, distinguished by the contours of its name definition. In time, our perception of the world has degenerated from a holistic grasping of it as a single system, to a perception of a space filled with individual items, each having a name. Every time we use language and assert something about the world, we reinforce this erroneous picture of the world" (Eno, 2019, p. 3).

At the same time, the pictogram of $w u$ does not simply present a still piece of flesh. It presents an action in which both components - subject and object in Western terms - are transformed. If we remember the famous Zhuanzi parable about Cook Ding who cuts up an ox, we might understand this mutuality as well as the meaning of action in the Chinese thought. I will consider this parable in the next section. Now I will only mention that, according to the Chinese thought, even such an action as cutting could be interpreted as a mutual communication and transformation. As Graham Parkes reveals,

\footnotetext{
${ }^{3} 29.09 .2019<$ https://en.wiktionary.org $/$ wiki/\%E4\%BA\%8B >

${ }^{4}$ 29.09.2019< $<$ https://hanziyuan.net/\#home $>$
} 
in Japanese aesthetics, for example, the notion of the 'cut' (ki-re 切れ) usually works as kire-tsuzuki 切れ続き, or 'cut-continuation' (Parkes, 2019).

We might conclude that reality in the Chinese thought is perceived in its suchness as a huge flow of living energy where the difference between things is relative and everything is regarded as a process that is transforming and relating with everything else, where transformations and relations are different aspects of the same processes: transformative relations and transformation in relations.

\section{The human being in the Chinese thought}

What is the place of the human being in this dynamic universe?

This question has not only one answer and could be regarded in different perspectives.

In terms of relations, the human being is one with the universe as everything else, taking part in complex mutual relations. At the same time, however, humans are beings that could resist to the natural flow of life cutting it into different pieces through their words and concepts. Therefore, being one with the wholeness of the universe, humans could feel and act as if they are separated. Humans and the human society are "the most volatile and unstable segment in nature" (Moeller, 2006, p. 56).

In terms of action, the human being is understood not as an acting subject, who imposes his will and intentions on the surrounding world, but as an integral part of the constant changes and transformations. The human being is not a passive object of influences of any external and alien will as well. In the Chinese thought everything is in mutual relation with everything else, each process is transformed by all others and in turn transforms them, drives everything else, and is driven by everything else. Processes flow through one another and everything "internal" is also "external", every "self" is also "another". Therefore, the dichotomies "active-passive", "I-others", "subject-object" are inapplicable here. In the constant transformation of the universe everything is in mutual and functional dependence with everything else.

From the perspective of value, the human is equal to everything else because in the flow of the Chinese universe there could not be a privileged position. In a world empty from entities there is no absolute reference point.

In Daoism, humans do not have a privileged position. They are as cosmic and natural as everything else is. As Hans Georg Moeller points out "human beings are one element or segment of the functioning of the cosmos... there is nothing special about humans. They were not created as the sole godlike species, are not the presumed master of the world, and are not even seen, in Heidegger terms, as the "shepherd of being". Not only do humans lack the role of dominating nature or a special relation and responsibility toward „,being”, they are not even recognised as cognitively privileged beings... Therefore... humans do not have a specific and unique "dignity"." (Moeller, 2006, p. 55).

The human position is only one of the possible positions: "When a man sleeps in the damp, his waist pains him and one side loses all sensation. Is that so of the loach? When he dwells in a tree he trembles in terror. Is that so of the ape? Which of these three knows the proper place to dwell?" (Zhuangzi, 2:17, 2019, p. 215).

In Confucianism, the human being has a unique position in the Universe because he has wen, 文 (writing, literature, culture, and civilisation). If, however, we trace the meaning and origin of 文, we will understand that this is the ability to see the pattern of movements in the cosmos and to act according to these patterns. Therefore, there is no opposition but harmony between human beings and the other part of the cosmos.

It is harmony that could be defined as the most privileged position in the Chinese universe. This is the position of balance when every process is in a perfect synchronicity with other processes.

According to Daoism, this is the position of the centre. In that, there is not only one centre, the centre could be revealed everywhere. In the middle of every process, there is an empty spring of its becoming. This is the position of a pure potentiality when no actualisation is yet realised and all the transformations are ahead and are possible. We may call this a zero position. Entering into this zero position could be interpreted as a circle-centred or centre-circled vision that is expressed in one of the names by which the Chinese denote themselves, 中國 or the Central state.

\footnotetext{
${ }^{5}$ Translation R. Eno
} 
While Daoism enters the deepest levels of world transformations, to the zero point of its becoming, Confucians observes the level of manifestation and reveal the patterns according to which the flow of the universe is unfolding: "Changes follow the rules (準) of Sky and Earth. Therefore, they can fulfil the ways (道) of Sky and Earth. Looking up, we observe the sky signs (文), looking down, we discern the earth principles (理)." (Xi Ci, Comments to the Associated Sentences, Upper Section, $4)^{6}$.

Sky signs and earth principles are patterns that the human being can distinguish within the constant flow of movements and transformation. In order to understand them he should look around up and down. This orientation gives a vertical correlation to the human being. He is situated between sky and earth (which in their combination form the universe) occupying again a middle position: "With the attainment of the mastery, (the sage) makes good his position in the middle (between heaven and earth)" (Xi Ci, Comments to the Associated Sentences, Upper Section, 1) ${ }^{7}$.

This vision is mirrored in the other name for China - Under Heaven, 天下.

So, in both Confucianism and Daoism the orientation according to the centre (the middle) is accentuated. This, however, does not mean orientation towards some substantive essence or an opposition towards other processes. On the contrary, this means losing the ego boundaries, opening to the becomings, nonattachment to the things, accepting processes as they come and leaving them when they go. This centred openness and peaceful fluidity makes the person in the Chinese tradition not "essentially defined (i.e. defined in terms of a unique essence one has that makes one a full-fledged person)" as it is in the Western tradition determined by Aristotle, but "progressively defined" (Santiago, 2008 , p. 5). This means that "an individual's nature is not pre-scripted simply in virtue of being born with a unique quality... That quality merely presents a range of opportunities for growth; they provide a set of possibilities for the ongoing development and maturation of one's changing nature" (ibid.).

Both teachings "belonged to the core patterns of orientations within which the ancient Chinese interpreted their position within the state and the cosmos" (Moeller, 2006, p. 2). In both cases, "the human being is not something we are; it is something that we do, and become... not an essential endowed potential, but what one is able to make of oneself." (Ames and Rosemon, 1998, p. 49).

Therefore, in Daoism fusion with dao means at the same time a forgetfulness of the "self", a forgetfulness of all restricting ideas and beliefs that make us feel as unchangeable entities separated from the wholeness of the universe. The centred man in Confucianism, entirely balanced and harmonious, is also plain, universal and as if imageless. There is nothing particular in him. Like a cloud, like water such a human could not be determined, they have no particular face, being everything and everywhere.

We should notice that Chinese texts speak exclusively about men. Maybe because these texts were assigned for rulers who were men. The other reason might be the fact that women have a deeper and more natural connection with the flow of life and therefore it is not necessary to teach them how to live.

\section{Ecological meaning of the understanding of the human position in the Cosmos}

In the last section, I will discuss the ecological implications of understanding the human in the Chinese culture. I regard here ecology in a broader or deeper philosophical sense as an attitude to nature and behaviour towards nature.

From the text above it is obvious that the Chinese thought presents a vision of oneness with nature, cosmos and universe. What should be the behaviour of man in accordance with this oneness?

In Daoism, the sage should achieve a pivot of Dao, the centre of transformation, 道枢 (Zhuangzi, $2^{8}$ ). This is the revealing of emptiness and peace within the flow of movements, the potentiality of void, the tranquillity of the ever-changing balancing on the ever-present moment of becoming, where all variable possibilities and responses are inexhaustible. Achieving this point of centring means fusing with the point of the ever-new birth or becoming of the world (Malyavin, 2016 ${ }^{9}$ ).

\footnotetext{
${ }^{6}$ 29.09.2019 <https://ctext.org/book-of-changes/xi-ci-shang >

${ }^{7}$ Ibid.

8 29.09.2019. <https://ctext.org/zhuangzi/adjustment-of-controversies >

${ }_{9}^{9}$ 29.09.2019.<https://tvkultura.ru/video/show/brand_id/20898/episode_id/972458/video_id/981529/ >
} 
"As soon as one finds this pivot, he stands in the centre of the ring (the circle of the processes), where he can respond without end to the changing views; without end to those affirming, and without end to those denying" (Zhuangzi, 2: 5, 1891, p. $36^{10}$ ).

As an example of such behaviour, we could remember the already discussed parable of Zhuangzi: "Cook Ding was carving an ox carcass for Lord Wenhui. With each touch of his hand, heave of his shoulder, step of his feet, thrust of his knee - whop! whish! - he wielded his knife with a whoosh, and every move was in rhythm. It was as though he were performing the Dance of the Mulberry Grove or keeping to the beat of the Constant Source music. "Ah, marvelous!" said Lord Wenhui. "Surely this is the acme of skill!" Cook Ding laid down his knife and replied, "What your servant loves, my lord, is the Dao, and that is a step beyond skill". At the beginning, when I first began carving up oxen, all I could see was the whole carcass. After three years I could no longer see the carcass whole, and now I meet it with my spirit and don't look with my eyes. Perception and understanding cease and spirit moves as it will. I follow the natural form" (Zhuangzi, 2: 17, 2019, p. $23^{11}$ ).

There are several important points about the behaviour of the master that we can learn from this parable: the comparison of the action with a dance and music and accentuating on the rhythm, the perception on the level of the subtle energy, the achieving of oneness in which the differences of the components are forgotten, entering into the wholeness inside the visible stability, following the patterns of the sky and suchness of the things. All these express the Daoist idea of non-doing, i.e. that perfect kind of doing where there is no division of subject and object but mutual harmony in which they simultaneously fulfil their potential.

In Confucianism, one should realise the patterns of the sky and earth allowing them to fulfil themselves through him. In such a way, he would be able to harmonise simultaneously himself and the world and to correspond adequately to the ever-new situations. He should not react to the situation after it has happened but be in such a synchronicity with it that to co-create it, co-creating himself at the same moment. This co-creation is not without a purpose. Corresponding to a situation, he should redirect it, using its power. However, it should not be in sake of some particular human ends, but for the sake of the whole. The purpose is harmony and fullness in unfolding the potential of every participant in the situation.

According to the Comments to "Yijing":

"There is a mutual resemblance between the sage and sky and earth, and hence there is no contrariety in him to them. His knowledge embraces all things, and his course is (intended to be) helpful to all under the sky; - and hence he falls into no error. He acts according to the exigency of circumstances without being carried away by their current; he rejoices in sky and knows its ordinations; - and hence he has no anxieties. He rests in his own (present) position, and cherishes (the spirit of) generous benevolence; - and hence he can love (without reserve). (Through the Yi), he comprehends as in a mould or enclosure the transformations of heaven and earth without any error; by an ever-varying adaptation he completes (the nature of) all things without exception; he penetrates to a knowledge of the course of day and night (and all other connected phenomena); - it is thus that his operation is spiritlike, unconditioned by place, while the changes which he produces are not restricted to any form." (Xi $\mathrm{Ci}$, Comments to the Associated Sentences, Upper Section, $4^{12}$ ).

The two kinds of behaviour could be understood as two aspects of synchronicity - one of the most important kinds of relations the Chinese thought has developed. Synchronicity implies mutuality, subject-object coherence and reciprocity of internal and external, microcosm and macrocosm.

Confucianism outlines the social aspect of these mutual connections - the attempt to keep human society in accordance with the cosmic processes. Therefore, rituals play an important role in it.

Daoism pays more attention to the interrelations of the human with the deepest levels of the universe. Therefore, yoga practices are important for it.

Combining inner and outer activity of harmonisation with reality, the Classical Chinese thought, which is most of all a guide for behaviour, prescribes such an attitude to nature that might be used as an example of wise ecological behaviour and could serve for the development of an ecological consciousness.

\footnotetext{
10 Translation J. Legge

11 Translation R. Eno

12 29.09.2019. $<$ https://ctext.org/book-of-changes/xi-ci-shang $>$
} 


\section{Conclusion}

This paper presented how the Classical Chinese thought understands the place of the human being in reality and the ecological potential of this understanding. Of course, the presented attitude and behaviour is an ideal that could not be followed by everyone. Nevertheless, it is important to know that there is a possibility of such an attitude to nature: achievement of the inner centre of oneness of everything as it is in Daoism and realising the patterns according to which changes happen, as it is in Confucianism. Not only do both teachings describe the universe, but they also prescribe the wise human behaviour if the universe is dynamic as it seems to be. What is more, they accentuate the responsibility of humans - if everything is in such complex relations and if everything influences everything else, it is obvious that every our action will respond to the entire universe.

\section{REFERENCES:}

Kobzev A.I. (1994)

Malyavin, V. (2016)

Malyavin, V., Vinogradskii B.

(1994)

Ames, R. T., Hall, D.

L. (2003)

Ames, R., Rosemont,

Jr. (1998)

Burik, S. (2009)

Burnet, J. (1892)

Eno, R. (2019)

Fenollosa, E., E.

Pound (1936)

Graham, A. C. (1959)

Girardot, N. J. at al. (2001)

Granet, M. (2008)

Jullien, Fr. (2004)

Moeller, H.-G. (2006)

Parkes, G. (2019)

Parmenides. (1892)

Santiago, J. (2008)

Zhuangzi (1891)

Zhuangzi (2019)
Кобзев, А. И. Ю - У "Наличие/бытие" - "отсутствие/небытие" - Китайская философия. Энциклопедический словарь. Москва: Мысль. (Kobzev, A. I. Yu You, The "Existence / Being" - "Absence / Non-Being" - Chinese philosophy. Encyclopedic Dictionary. Kitayskaya filosofiya. Entsiklopedicheskiy slovar' Moskow: Misl')

Малявин, Вл.Китай в современном мире. 1 лекция. ACADEMIA. (Malyavin, Vladimir. 2016. China in the modern world. 1 lecture. ACADEMIA.) (23.06.2019) $<$ https://tvkultura.ru/video/show/brand_id/20898/episode_id/972458/video_id/981 $\underline{529 />}$

Антология даосской философии, Москва: Товарищество. (Malyavin, V., Vinogrodskij B. Antologija daosskoj filosofii, Moskow: Tovarishtestvo)

Daodejing, "Making this Life Significant", New York: Ballantine Books.

"Introduction" to The Analects of Confucius: A Philosophical Translation, New York: Ballantine Pub. Group.

The End of Comparative Philosophy and the task of Comparative Thinking. New York: State University of New York.

Early Greek Philosophy. London and Edinburgh: Adam and Charles Black.

Introduction to Zhuangzi: The Inner Chapters.

(23.06.2019) <http://www.indiana.edu/ p374/Zhuangzi.pdf >

The Chinese Written Character as a Medium for Poetry. London: City Lights Books.

"Being" In Western Philosophy Compared with Shih/Fei and You/Wu In Chinese Philosophy - Asia Major. Vol. 7. N 1-2. 1959. pp. $79-112$.

Daoism and Ecology: Ways within a Cosmic Landscape. N.J. Girardot, J. Miller and L. Xiaogan (eds), Harvard University Press, Cambridge.

Китайская мысль от Конфуция до Лаоцзы, Москва: Алгоритм. (Chinese thought from Confucius to Laozi, Moskow: Algorithm.)

A Treatise on Efficacy: Between Western and Chinese Thinking (Traité de l'efficacité), University of Hawaii Press, Honolulu.

The Philosophy of the Daodejing", New York: Columbia University Press.

Making the Cut / Keeping the Continuity. A Zen Approach to Living Aesthetically. Paper presented at the International Haiku conference, 8 June 2019, Sofia.

On Nature. In: Burnet, J. Early Greek Philosophy. London and Edinburgh: Adam and Charles Black.

Confucian Ethics in the Analects as Virtue Ethics. Philosophical Ideas and Artistic Pursuits in the Traditions of Asia and the West: An NEH Faculty Humanities Workshop. Paper 8. (23.06.2019) <http://dc.cod.edu/nehscholarship/8>

Zhuangzi. Inner chapters, The Sacred Books of China: The Texts of Taoism. tr. J. Legge, Oxford: Clarendon Press.

Zhuangzi. Inner chapters, Early Chinese Thought, Indiana University, tr. R. Eno (23.06.2019) <http://www.indiana.edu/ p 374/Zhuangzi.pdf $>$ 